\title{
The Study of Tool Wear About Ceramic Cutting Tool Processing Mechanism of Super-alloy
}

\author{
Zhao Can ${ }^{1, a^{*}}$,Tao GuangFu ${ }^{1, b}$,Liu Yubo ${ }^{1, \mathrm{c}}$,Guo Yanyan ${ }^{1, \mathrm{~d}}$ and Zhang Yanhui ${ }^{2, \mathrm{e}}$ \\ ${ }^{1}$ Heilongjiang University of Science and Technology, Harbin, 150022, China \\ ${ }^{2}$ North Hua'an Industrial Group Co. Ltd. Heilongjiang Qiqihar, 161006 \\ azhaocan_hist@163.com, ${ }^{a}$ taoguangfu@163.com,cysclx@126.com, \\ d497304886@qq.com, ${ }^{e} 2586478086 @ q q . c o m$
}

\begin{abstract}
Separately using two different types of ceramic cutting tool, through the experiments of ceramic cutting tool to study the processing of super-alloy of tool wear, compare the two processing the cutting tool wear condition, and further analysis of the wear mechanism of ceramic cutting tool process, and get the related conclusion.
\end{abstract}

Keywords: super-alloy, Ceramic cutting tool, Tool wear, Milling

\section{Introduction}

Nickel base alloy as a new type of materials are widely used in aerospace. Because the nickel base high-temperature alloy belongs to difficult to cut materials, so the choice of cutting tool in machining is very important. As one of excellent properties cutting tools and with high temperature characteristics, the ceramic tool is suitable for the cutting of high temperature alloy, however, the cost of the ceramic tools is very high. So we can do the simulation of wear of ceramic tools by the finite element method to save the experimental cost and verify the tool life. The goal the simulation of cutting is that combine the technology of the machining and the finite element method to establish related model and do the simulation of cutting.

\section{The Tool Wear Experiment}

\subsection{The Experimental Equipment}

Workpiece material:Nickel base high temperature alloy.The tools material:One is $\mathrm{Al}_{2} \mathrm{O}_{3}-\mathrm{SiC}_{\mathrm{w}}$ ceramic tool the grade WG300 and the other is $\mathrm{Si}_{3} \mathrm{~N}_{4}-\mathrm{Al}_{2} \mathrm{O}_{3}$ ceramic the grade CC6060.rake angle-60 ,flank angle 60 and cutting edge inclination angle-60in both of The two tools. Experimental machine: MC120-60 CNC vertical Machining center,shown in fig.1.The high speed of machine 12000r/min;cutting conditions:dry cutting.

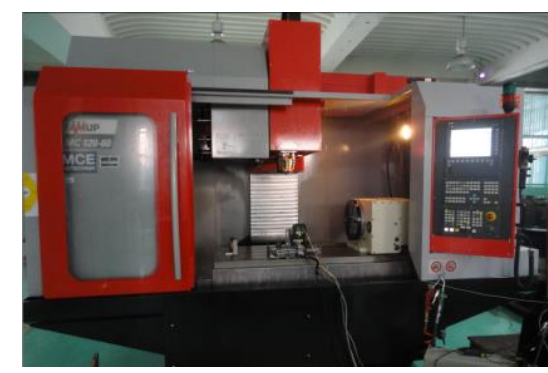

Figure 1. MC120-60 CNC Vertical Machining Center 


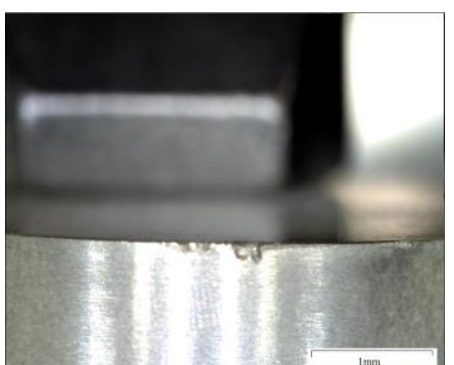

(a) WG300 cutting speed $720 \mathrm{~m} / \mathrm{min}$

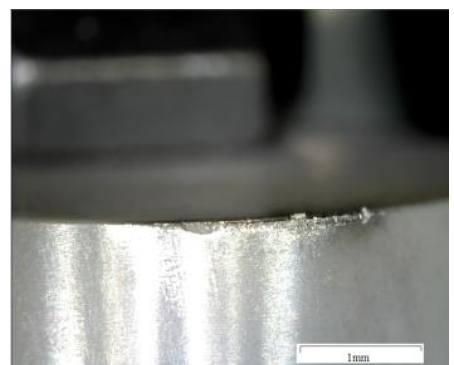

(b) CC6060cutting speed $720 \mathrm{~m} / \mathrm{min}$

\section{Figure 2. Shape Cutters Wear after Ceramic Cutting Tool}

\subsection{The Measurement Conditions of Tool Wear}

The standard of blunt: the value of flank blunt $V B>0.02 \mathrm{~mm}$, Groove blunt $\mathrm{VN}>0.05 \mathrm{~mm}$ cutting edge seriously tipping, tool surface peeling or be damaged. When meet any one standard above,we visual the condition as the tool blunt and stop the cutting. By means of Dino-Lite digital microscope, take the photo of the wearing surface of the tool flank, and measure the wearing value of tool flank surface VB and groove wearing value. If the tools reach the blunt standard, we would analysis its surface morphology and energy spectrum.

\section{Experimental Result and Analysis}

\subsection{The Comparison of the Performance Ceramic Cutting Tools}

Because of the difference of the physical and mechanical properties existing ,there would be great difference in the tool performance in different cutting conditions. The whisker in $\mathrm{Al}_{2} \mathrm{O}_{3}-\mathrm{SiC}_{\mathrm{w}}$ whisker toughening ceramic cutting tool is single crystal.with certain fibrous structures, the average diameter of the whisker is $0.5 \sim 1 \mathrm{~mm}$, the average length is $10 \sim 80 \mathrm{~mm}$, the tensile strength reach 7Gpa.The Sic whisker play the role of reinforcing rod in the $\mathrm{Al}_{2} \mathrm{O}_{3}$ matrix. This whisker could effectively prevent the expansion of micro crack and disperse the stress in the matrix.This method enforcing the fabric could improve the fracture toughness of base material significantly. At the same time, the high thermal conductivity of the Sic whisker easily take the cutting heat. So the heat stress produced by temperature gradient in the tool matrix was reduced.The thermal stability of overall whisker was improved[1]The $\mathrm{Si}_{3} \mathrm{~N}_{4}-\mathrm{Al}_{2} \mathrm{O}_{3}$ in (Sialon)ceramic tool is a single-phase material. Sialon is obtained by replacing the nitrogen part with oxygen part and at the same time replacing the Silicon part with Aluminum part on the base of $\mathrm{Si}_{3} \mathrm{~N}_{4}$. Adding $\mathrm{Y}_{2} \mathrm{O}_{3}$ in the Sialon would lead to the densification of the organization. With high strength and toughness, Sialon ceramic tool has better anti impact performance than other ceramic tools.In addition,this kind of ceramics has also a good seismic performance.We chose cutting speed $V=800 \mathrm{~m} / \mathrm{min}$, the amount of feed $f=0.06 \mathrm{~mm} / \mathrm{t}$,cutting depth $C=1 \mathrm{~mm}$ as the experimental condition.In this condition, when cutting time reach $30 \mathrm{~s}$ and $60 \mathrm{~s}$, we observe the tool flank wearing value $V B$ and the groove wearing value $V N$. The wear condition is shown as followed figure 3 , the wear value is shown as table 1 .

Table 1. Ceramic Cutting Tool after the Blade Wear VB and Groove Wear VN

\begin{tabular}{|l|l|l|}
\hline Tool grade & Cutting speed:720m/min & Cutting speed:864m/min \\
\hline
\end{tabular}




\begin{tabular}{|c|c|c|c|c|}
\hline & $V B(\mathrm{~mm})$ & $V N(\mathrm{~mm})$ & $V B(\mathrm{~mm})$ & $V N(\mathrm{~mm})$ \\
\hline WG300 & 0.1 & 0.17 & 0.09 & 0.15 \\
\hline CC6060 & 0.07 & 0.13 & 0.06 & 0.12 \\
\hline
\end{tabular}

When the cutting speed is $720 \mathrm{~m} / \mathrm{min}$, the wear shape is inverted triangle. The flank tool wear value VB and the groove wear value of WG300 are both bigger than that of CC6060. The groove of $\mathrm{Al}_{2} \mathrm{O}_{3}-\mathrm{SiC}_{\mathrm{w}}$ whisker toughening ceramic tool has large opening along the cutting edge direction. The defect area of tool in groove of $\mathrm{Al}_{2} \mathrm{O}_{3}-\mathrm{SiC}_{\mathrm{w}}$ whisker toughening ceramic tool is bigger than that of Sialon ceramic tool. The defect area in Sialon ceramic tool groove is the smallest. Because there is great difference in $\mathrm{Al}_{2} \mathrm{O}_{3}-\mathrm{SiC}_{\mathrm{w}}$ whisker toughening tool and Sialon ceramic tool in the same cutting conditions, we would study the different wear mechanism of two kind of ceramic tool.

\subsection{The Analysis of Tool Durability}

In the tool durability experiment, to reduce the ceramic tool cut-in and cut-out time, we set the tool time interval measurement to 30s. when the tool flank blade wear value $V B$ or the groove wear value $V N$ reach the standard of wear blunt, we stop the experiment. The wear blunt standard and wear value of $\mathrm{Al}_{2} \mathrm{O}_{3}-\mathrm{SiC}_{\mathrm{w}}$ whisker toughening ceramic tool WG300 and Sialon ceramic tool CC6060 are shown in table2. Other parameter is cutting depth: $1 \mathrm{~mm}$. The feed peer tooth: $1 \mathrm{~mm} / \mathrm{z}$.

Table 2. Two Cutting Time and at Different Speeds of the Cutting Tool Wear Value

\begin{tabular}{|c|c|c|c|c|c|c|c|}
\hline \multirow{2}{*}{$\begin{array}{l}\text { Experi- } \\
\text { mental } \\
\text { number }\end{array}$} & \multirow{2}{*}{$\begin{array}{l}\text { Cutting } \\
\text { speed } \\
(\mathrm{m} / \mathrm{min})\end{array}$} & \multicolumn{3}{|c|}{ CC6060 } & \multicolumn{3}{|c|}{ WG300 } \\
\hline & & $\begin{array}{l}\text { Cutting } \\
\text { time } \\
(\mathrm{min})\end{array}$ & $\begin{array}{c}V B \\
(\mathrm{~mm})\end{array}$ & $\begin{array}{c}V N \\
(\mathrm{~mm})\end{array}$ & $\begin{array}{l}\text { Cutting } \\
\text { time } \\
(\min )\end{array}$ & $\begin{array}{c}V B \\
(\mathrm{~mm})\end{array}$ & $\begin{array}{c}V N \\
(\mathrm{~mm})\end{array}$ \\
\hline 1 & 720 & 2 & 0.20 & 0.34 & 1.5 & 0.19 & 0.51 \\
\hline 2 & 864 & 2.5 & 0.23 & 0.35 & 1 & 0.50 & 0.34 \\
\hline 3 & 1080 & 2 & 0.26 & 0.38 & 1 & 0.17 & 0.60 \\
\hline
\end{tabular}

For WG300, the main failure form is groove wear. When the cutting speed is $864 \mathrm{~m} / \mathrm{min}$, there is the emergency of edge collapse and the flank blade wear value is greatly beyond the wear standard. When the cutting speed is $720 \mathrm{~m} / \mathrm{min}$, the cutting time is the longest. However, for CC6060, the main failure form is flank wear. When the cutting speed is $864 \mathrm{~m} / \mathrm{min}$, the cutting time is the longest, reaching $2.5 \mathrm{~min}$ In summary, the performance of Sialon ceramic tool CC6060 is better than $\mathrm{Al}_{2} \mathrm{O}_{3}-\mathrm{SiC}_{\mathrm{w}}$ whisker toughening tool WG300. There existing great difference in the two tools wear process. The main failure form of WG300 is groove wear blunt, however, the CC6060 is flank blade wear.

\subsection{Ceramic Tool Wear and Damage Morphology}

We observe and analysis the rake face and flank blade wear shape by use of scanning electron microscope. When we use the ceramic tools cutting the Nickel base superalloy, find the main wear shape are that rake face wear, flank blade wear and groove wear, the main damage shape are that the edge collapse of cutting edge, the surface spalling and tool nose broken. WG300 wear shape is shown as figure 4 . 


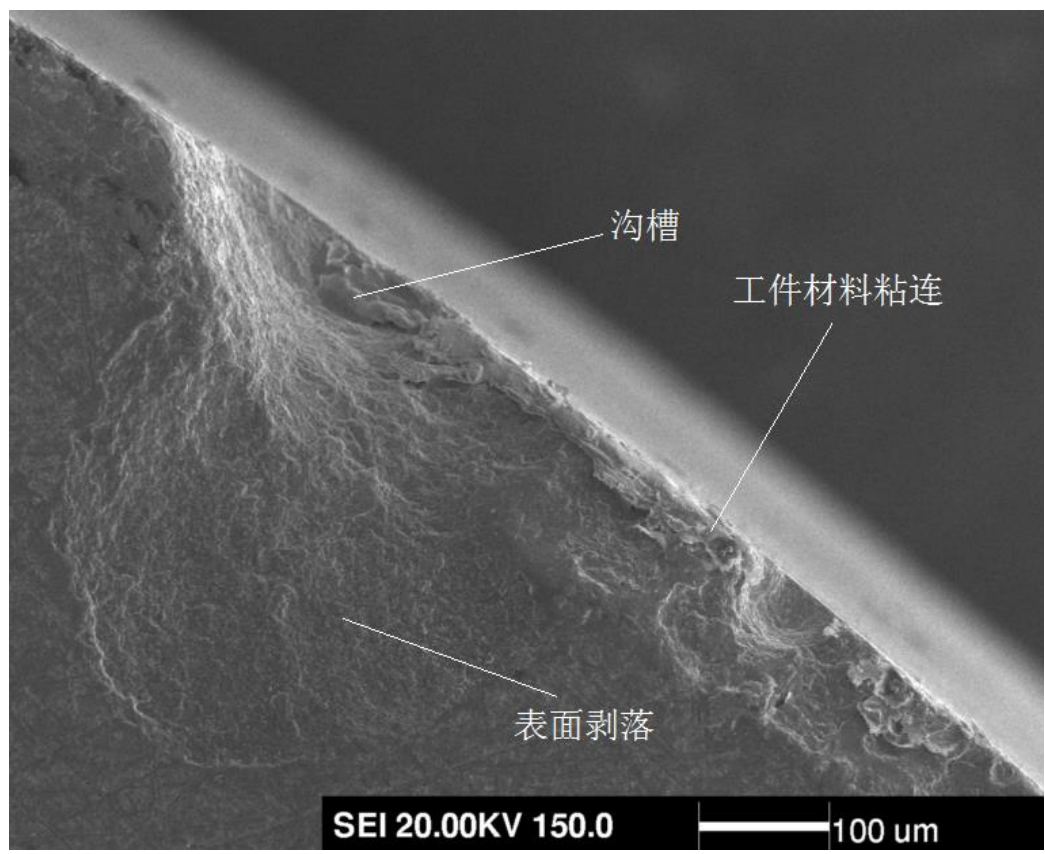

Figure 3. WG300 Wear Morphology

There are formation of flaking in the tool surface and groove in the cutting depth end. Flank wear uniform and the workpiece material adhesion phenomenon can also be seen in the fig. 4. CC6060 wear shape is shown as fig.5. As can be seen, there are the phenomenon as edge collapse ,not obvious groove, the material adhesion and surface spalling.From the analysis of wear shape in WG300 and SX9, we can see in the ceramic tool process there are always wear. The brittleness of the ceramic tool is big but the fracture toughness and tensile strength is relatively low. ceramic tool being sintered powder material, the organization of the tool is uneven. There are random distributed internal micro defects and voids .so it is easy to cause the cutter brittle damage[3]. When the ceramic tool cut Nickel base superalloy GH4169, the formed chip is usually break chip. Because the time of chip contact rake face is short, so the cutting force and heat will concentrate in the cutting edge. The ceramic toughness being relatively low, under the alternating stress, it is easy to produce micro cracks along grain boundaries. WG300 micro cracks in the cutting edge are shown as fig.5(a).Under the effect mechanical stress, heat stress and workpiece material adhesion ,the micro crack will expand gradually and finally result in collapse edge of cutting edge and tool surface peeling. The micro cracks range of CC6060 is larger than WG300, almost covering the whole cutting edge. Shown as fig. $5(\mathrm{~b})$. 


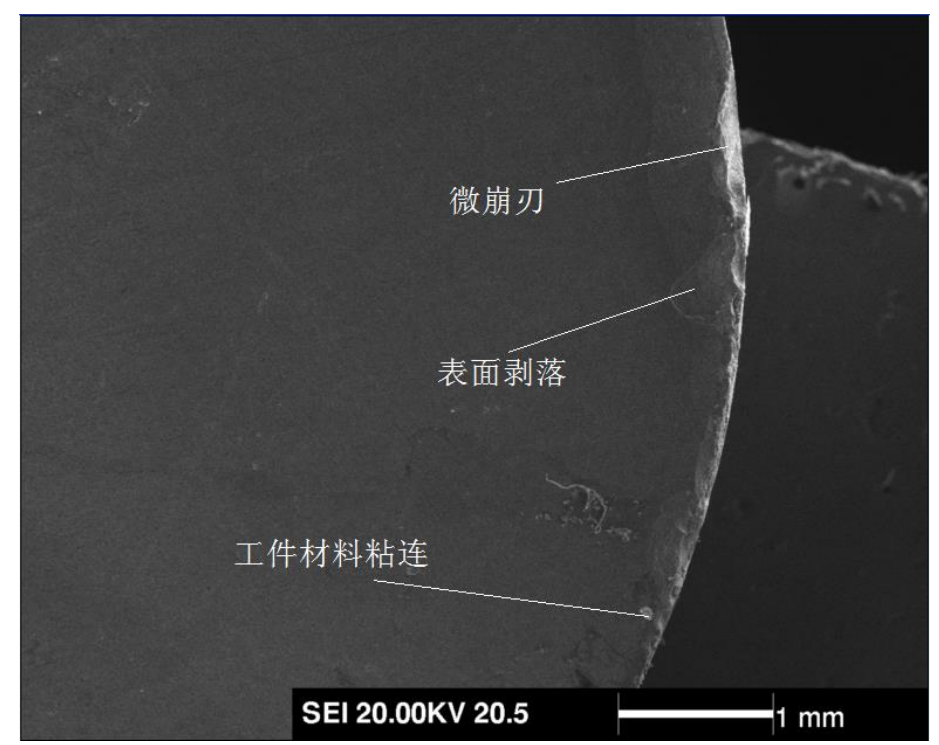

Figure 4. CC6060 Wear Morphology

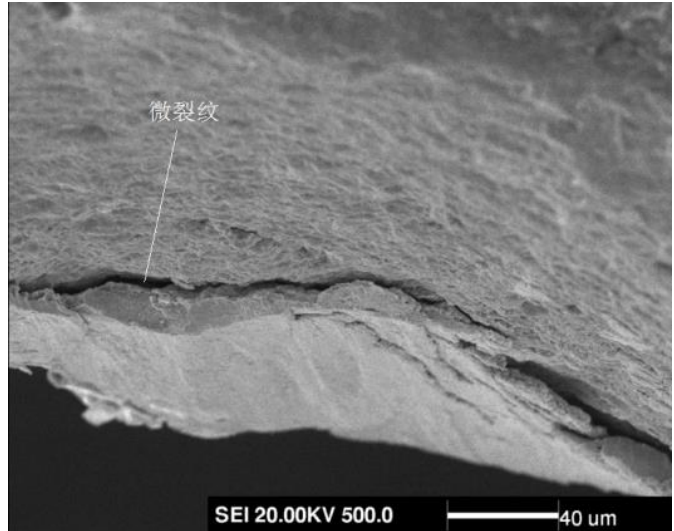

(a) WG300 micro cracks along the cutting edge

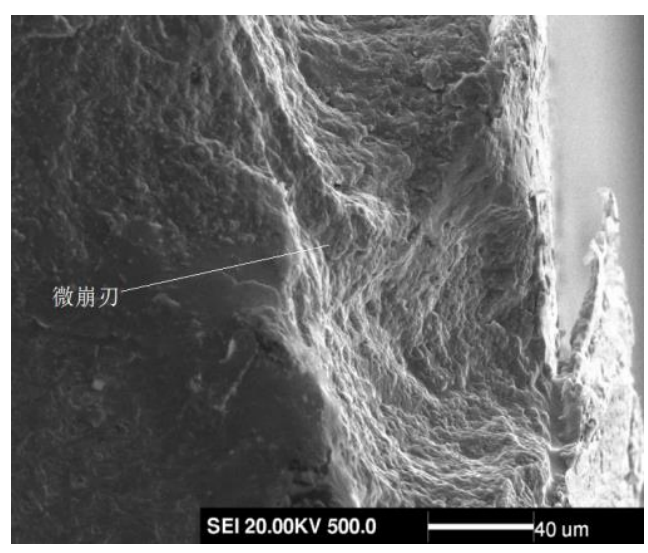

(b)CC6060 micro edge collapse

Figure 5. Brittleness Damage of Ceramic Cutting Tool

\section{Conclusion}

In the process of ceramic tool cutting superalloy, from the simulation -analysis and experimental study on the mechanism of the tool wear, we can get the conclusion as flow:

(1)There is big difference in the wear shape of $\mathrm{Al}_{2} \mathrm{O}_{3}-\mathrm{SiC}_{\mathrm{w}}$ whisker toughening ceramic tool and that of Sialon ceramic tool.The flank blade wear value VB is far more than $\mathrm{Al}_{2} \mathrm{O}_{3}-\mathrm{SiC}_{\mathrm{w}}$ whisker toughening ceramic tool, but the groove wear value of Sialon ceramic tool is lower than $\mathrm{Al}_{2} \mathrm{O}_{3}-\mathrm{SiC}_{\mathrm{w}}$ whisker toughening ceramic tool.

(2)The main failure form of $\mathrm{Al}_{2} \mathrm{O}_{3}-\mathrm{SiC}_{\mathrm{w}}$ whisker toughening ceramic tool WG300 is groove wear but Sialon ceramic tool CC6060 is flank blade wear. The anti flank blade ability of WG300 is stronger than CC6060, but, the anti groove wear ability is weaker than CC6060.The two kind of ceramic tools are applicable to different cutting speed.

(3) When using the ceramic tool cutting the Nickel superalloy GH4169, the main wear shape are that :the rake wear, flank blade wear and groove wear along the cutting line. 
(4)when the tool cut the Nickel base superalloy,the workpiece adhesion is still very serious. The effect of this adhesion resulted in the surface inhibition and peeling in ceramic tool.

\section{Acknowledgements}

This work was supported by the national natural Science Found (Project No 51075128 and 51405138) and the national Science Foundation of Heilongjiang Province (Project No QC2012C029).

\section{Reference}

[1] S. G. Xiao, "Cutting tool materials and their reasonable selection", Mechanical industry press, (1990).

[2] S G. Xiao, "Modern cutting tool material", Chongqing university press, (1992).

[3] X. Ai, "High-speed machining technology", Defense Industry Press, (2003).

[4] S. K. Bhattacharyya, A. Jawaid, J. Wallbank, "Wear of Sialon tooling in the high-speed machining of aerospace materials", The winter annual meeting of the American Society of Mechanical Engineers, (1984); New Orleans, Louisiana, USA.

[5] NTK Cutting Tools, "Solutions for the aerospace industry: Machining high-temperature alloys with ceramics", vol. 42-49, (2007-2008).

[6] T. Cui, J. Q. Wan, X. X. Wang, "Alloy GH4169 was investigated high temperature oxidation characteristics", Journal of corrosion science and protection technology, vol. 16, (2004), pp.192-195.

[7] L.J. Xie, "Estimation of Two-dimension Tool Wear Based on Finite Element Method", Universitat Karlsruhe, (2003)

[8] Y. Wan and X. Ai, "Tool wear and fracuter in high speed milling aluminum alloy", Chinese journal of mechanical engineering, vol. 43, no. 4, (2007), pp. 103-107.

[9] D.Q. Gao , Z.Y. Li and Z.Y. Mao, "Modular Machine tool Automatic Manufacturing technique", vol. 12, (2010), pp. 10-12. 